\title{
VARIAÇÃO NOS ATRIBUTOS DO SOLO EM SISTEMAS DE MANEJO COM ADIÇÃO DE CAMA DE FRANGO(1)
}

\author{
Franciele Caroline de Assis Valadão(2), Kelly Dayana Benedet \\ Maas $^{(3)}$, Oscarlina Lúcia dos Santos Weber ${ }^{(4)}$, Daniel Dias Valadão \\ Júnior ${ }^{(5)} \&$ Tonny José da Silva ${ }^{(4)}$
}

\begin{abstract}
RESUMO
A cama de frango constitui-se em adubo orgânico com boas características agronômicas, podendo ser bom condicionador das propriedades físicas do solo. Assim, o objetivo deste trabalho foi verificar alterações nas propriedades do solo em sistemas de plantio direto com adição de cama de frango. $O$ estudo foi feito em três camadas $(0-10,10-20$ e $20-30 \mathrm{~cm})$ e três repetições, em Latossolo VermelhoAmarelo distrófico submetido a plantio direto contínuo nos últimos anos, com rotação principalmente de soja, milho, algodão e milheto. Os tratamentos foram: sistema com adubação mineral (S2), com adição de cama de frango crua (S3), com adição de cama de frango compostada (S4) e uma área não manejada de Cerrado nativo (S1). Os sistemas de manejo induziram em ordem crescente - S4, S2, S3 - à degradação dos atributos do solo em relação à vegetação nativa (S1), e isso foi quantificado pelos menores valores de carbono total, diâmetro e estabilidade de agregados, macroporosidade e condutividade hidráulica saturada e pelos maiores valores de densidade e resistência do solo à penetração e microporosidade. A cama de frango crua revelou-se mais vantajosa na disponibilidade de nitrogênio total e menos eficiente em garantir a qualidade física do solo. A cama de frango compostada proporcionou atributos mais semelhantes às condições naturais.
\end{abstract}

Termos de indexação: resíduo orgânico de avicultura, composto de aviário, propriedades físicas do solo.

\footnotetext{
(1) Recebido para publicação em 29 de setembro de 2010 e aprovado em 2 de setembro de 2011.

(2) Professor do Instituto Federal de Educação, Ciência e Tecnologia de Rondônia - IFRO. Campus Cacoal. Rodovia BR 364, Km 228, Lote 2, CEP 76960-730 Cacoal (RO). E-mail: franciele.caroline@ifro.edu.br

(3) Doutoranda em Agricultura Tropical pela Universidade Federal de Mato Grosso - FAMEV/UFMT. E-mail: kelly_bmaas@hotmail.com

(4) Professor Adjunto do Departamento de Solos e Engenharia Rural, FAMEV/UFMT. E-mails: oscsanwb@cpd.ufmt.br; tonny.silva@pq.cnpq.br

(5) Professor do Instituto Federal de Educação, Ciência e Tecnologia de Mato Grosso - IFMT. Campus São Vicente. Email: daniel.junior@svc.ifmt.edu.br
} 


\title{
SUMMARY: VARIATION IN SOIL PROPERTIES BY MANAGEMENT SYSTEMS WITH APPLICATION OF POULTRY LITTER
}

\begin{abstract}
Poultry litter is an organic fertilizer with good agronomic characteristics, which serves well as conditioner of soil physical properties. In this sense, the objective of this study was to verify changes in soil properties in no-tillage systems with poultry litter. The study was conducted on a sandy loam Oxisol under continuous no-tillage in the last years, with rotation of mainly soybean, corn, cotton, and millet, with evaluations in three layers $(0-10,10-20,20-30 \mathrm{~cm})$, in three replications. The treatments consisted of a mineral fertilizer system (S2), application of raw poultry litter (S3), application of chicken manure compost (S4) and an untreated area with native vegetation (S1). The management systems induced the degradation of soil properties in relation to native vegetation (S1) in ascending order - S4, S2, S3, which was quantified by the reduced values of total carbon, aggregate diameter and stability, macroporosity, hydraulic conductivity saturated and higher values of density and resistance to penetration and microporosity. Raw poultry litter was more advantageous for the availability of total $N$ and less efficient to ensure the soil physical quality. Composted chicken litter resulted in properties that were more similar to natural conditions.
\end{abstract}

Index terms: organic poultry waste, poultry compost, soil physical properties.

\section{INTRODUÇÃO}

O aumento do custo de fertilizantes inorgânicos de elevada solubilidade e reduzida ação condicionadora do solo tem direcionado a atenção de pesquisadores e produtores agrícolas para utilização de adubos orgânicos obtidos a partir de fontes disponíveis em cada localidade. A utilização frequente de adubos orgânicos contribui para o aumento dos estoques de matéria orgânica no solo. Essa matéria caracterizase por apresentar baixa densidade (Celik et al., 2004) e capacidade de aumentar a estabilidade de agregados (Castro Filho et al., 1998), o que contribui para elevação da porosidade e melhoria na estrutura do solo (Barzegar et al., 2002). Por essa razão, favorece a maior disponibilidade e retenção de água no solo (Barzegar et al., 2002; Celik et al., 2004) e menor resistência à penetração das raízes (Mosaddeghi et al., 2009).

A adição de fertilizante orgânico obtido a partir de cama de frango pode contribuir para a melhoria das características físicas, químicas e biológicas do solo. Com a intensificação da produção de frango de corte, principalmente com aumento do índice de conversão alimentar e redução do tempo de criação com a utilização de rações mais concentradas (Girotto \& Mieli, 2004), o volume de resíduos gerados por essa atividade também aumentou. Entretanto, a cama de frango - mistura de palha com as fezes das aves, restos de ração e pena - é rica em carbono, cerca de $39 \%$ (Adeli et al., 2007), e nutrientes (Boateng et al., 2006; Adeli et al.; 2007; Costa et al., 2009). Por geralmente estar disponível nas propriedades agrícolas a baixo custo, tem sido frequentemente utilizada pelos produtores na adubação.

Muitos estudos têm sido feitos para demonstrar a viabilidade desse resíduo como fertilizante em culturas como sorgo (Santos et al., 2004), soja (Adeli et al., 2005), milho (Boateng et al., 2006) e algodão (Adeli et al., 2007). Embora os resultados sejam promissores, pouco se conhece sobre a influência desse fertilizante sobre os atributos físicos do solo. Costa et al. (2009) estudaram esse material como potencial de recuperação física de um Latossolo Vermelho sob pastagem degradada e verificaram redução na densidade e na porosidade total proporcional ao aumento da aplicação do resíduo. De forma semelhante, Adeli et al. (2007), aplicando doses anuais de $6,7 \mathrm{Mg} \mathrm{ha}^{-1}$, ao fim de três anos de estudo, verificaram aumento de 18,20 e $34 \%$ no $\mathrm{N}$ e $\mathrm{C}$ total e estabilidade de agregados do solo, respectivamente, em comparação com o tratamento com adubo mineral.

No entanto, os resultados ainda são insuficientes para recomendação do uso de cama de frango como condicionador físico do solo e, muitas vezes, é possível verificar pouca ou nenhuma alteração no solo com a utilização desse resíduo (Franzluebbers et al., 2001; Lunardi Neto et al., 2008). Assim, o objetivo deste trabalho foi verificar alterações nas propriedades físicas e no carbono total do solo devido à adição de cama de frango crua e compostada.

\section{MATERIAL E MÉTODOS}

O estudo foi realizado em Latossolo VermelhoAmarelo distrófico (Embrapa, 2006), textura francoargiloarenosa, na Fazenda Pirassununga, Campo Verde - MT, sentido BR 364, sob coordenadas geográficas de $15^{\circ} 37^{\prime} 00,6^{\prime \prime} \mathrm{S}$ e $55^{\circ} 11^{\prime} 18,8^{\prime \prime} \mathrm{W}$, a uma altitude de $736 \mathrm{~m}$. A fazenda possui regime de agricultura intensiva desde 1960. O clima da região é classificado como Aw segundo Köppen, com temperatura média variando entre 18 e $24^{\circ} \mathrm{C}$, mínima 
próxima aos $10{ }^{\circ} \mathrm{C}$ e máxima entre 29 e $34{ }^{\circ} \mathrm{C}$. A precipitação pluvial anual é de 1.421 a $1.700 \mathrm{~mm}$, e o período de chuva normalmente é de outubro a maio, com estiagem de junho a setembro.

Estudaram-se os sistemas de manejo: vegetação nativa-Cerrado (S1); plantio direto com adubação mineral (S2); plantio direto com adição de cama de frango crua (S3); e plantio direto com adição de cama de frango compostada (S4), que constituíram os tratamentos. Amostras de solo dessas áreas foram coletadas na profundidade de 0-10, 10-20 e 20-30 cm e caracterizadas a posteriori. Esses tratamentos foram dispostos em delineamento experimental inteiramente casualizado, em esquema de parcelas subdivididas $4 \times 3$, com três repetições, sendo as parcelas formadas pelos sistemas de manejo e as subparcelas, pelas camadas de solo amostradas.

A mata nativa de Cerrado, por não ter sofrido alteração antrópica, foi utilizada como referência para mensurar o grau de degradação dos demais sistemas. No sistema de plantio direto com adubação mineral, a rotação de cultura foi feita com soja/milho e algodão/ milheto; após sete anos de plantio direto contínuo, foi realizado o revolvimento do solo na safra de 2006/2007, com duas gradagens; a partir de então não houve mais revolvimento. Foi realizada calagem na safra de 2008/ 2009 e adubação com NPK em cada plantio, sendo o NK aplicado em cobertura. No sistema com cama de frango crua e com cama de frango compostada, aplicada em cobertura sem incorporação, o plantio direto foi realizado de maneira contínua no decorrer dos últimos oito anos. No S3, a rotação ocorreu entre soja/milho, mantendo-se descanso da área na safra de 2009/2010 e plantio de milho na safrinha; havia aplicação de $2,5 \mathrm{Mg}_{\text {ha }}{ }^{-1}$ do resíduo há quatro anos consecutivos, com calagem realizada na safra de 2007/ 2008 e fornecimento de $\mathrm{P}$ e K sempre que necessário. No $\mathrm{S} 4$, a rotação ocorreu com soja/milho e algodão/ milheto; houve fornecimento de cama de frango crua por quatro anos, intercalado por dois anos sem aplicação, ocorrendo nos últimos dois anos aplicação do resíduo na dose de $2,5 \mathrm{Mg} \mathrm{ha}^{-1}$, após ter passado por um processo de compostagem. Nesse mesmo sistema, na safra de 2006/2007 foi realizada gessagem e calagem, bem como a correção do solo com P e K anterior à implantação de cada cultura. Nos sistemas S3 e S4, a adubação orgânica ocorreu de forma complementar e houve correção de $\mathrm{N}$ no plantio, sem adubação de cobertura, sendo o resíduo orgânico fornecido anteriormente ao plantio de cada cultura. A dose de resíduo foi estipulada respeitando-se a legislação pertinente.

A compostagem da cama de frango (composta por casca de arroz, esterco das aves, restos de ração e pena) foi realizada com o auxílio de um sistema agitadoraerador (equipamento movido por motor elétrico, com deslocamento e velocidade programada). Esse agitador revolvia o material aproximadamente seis vezes por dia, como forma de aumentar a aeração e acelerar o processo de decomposição, estabilizando o composto em apenas 18 dias. Durante o processo, a umidade era monitorada e mantida próxima a $55 \%$. A composição química, média de cada aplicação, da cama de frango crua e compostada está apresentada no quadro 1.

As áreas sobre plantio direto foram cultivadas com milho cultivar BR 106. Em abril de 2010, dez semanas após a emergência da cultura (florescimento e polinização - estádio R1), as amostras de solo foram coletadas. Em cada sistema de manejo, área de aproximadamente 1,5 ha foi dividida em três partes, constituindo-se as repetições. Essas partes foram amostradas em três profundidades: 0-10 cm (P1), 10$20 \mathrm{~cm}$ (P2) e 20-30 cm (P3).

Em cada parcela foi definido e identificado um ponto de amostragem, tomando-se cinco leituras de resistência do solo à penetração (RSP), dispostas em forma radial até a profundidade de $30 \mathrm{~cm}$. Para isso, foi utilizado um penetrógrafo eletrônico automático manual, com velocidade de penetração constante de $30 \mathrm{~mm} \mathrm{~s}^{-1}$ e cone de $129,28 \mathrm{~mm}^{2}$ de área de base, desenvolvido por Bianchini et al. (2002).

Paralelamente às leituras de RSP, foram abertas minitrincheiras para coleta de amostras de solo com estrutura preservada em cada profundidade, utilizando anel metálico de $50 \mathrm{~mm}$ de diâmetro e $50 \mathrm{~mm}$ de altura $\left(98,17 \mathrm{~cm}^{3}\right)$. Além destas, coletaram-se também amostras de solo com estrutura semipreservada, para determinação da estabilidade de agregados, e amostras deformadas, para caracterização química, granulométrica e conteúdo de água no momento da coleta. Estas análises foram realizadas no Laboratório de Física de Solo da Faculdade de Agronomia e Medicina Veterinária, na Universidade Federal de Mato Grosso, em Cuiabá-MT.

Quadro 1. Caracterização química da cama de frango utilizada nos sistemas de manejo

\begin{tabular}{lcc}
\hline \multirow{2}{*}{ Característica } & \multicolumn{2}{c}{$\begin{array}{c}\text { Composição base seca }\left(\mathbf{1 1 0}{ }^{\circ} \mathbf{C}\right) \\
\text { Cama de frango }\end{array}$} \\
\cline { 2 - 3 } & Crua & Compostada \\
\hline & & \\
$\mathrm{pH} \mathrm{em} \mathrm{CaCl}_{2} 0,01 \mathrm{~mol} \mathrm{~L}^{-1}$ & 8,0 & 8,8 \\
Carbono total $\left(\mathrm{g} \mathrm{kg}^{-1}\right)$ & 243,0 & 245,3 \\
$\mathrm{~N}$ total $\left(\mathrm{g} \mathrm{kg}^{-1}\right)$ & 40,0 & 17,5 \\
$\mathrm{P}$ total $\left(\mathrm{g} \mathrm{kg}^{-1}\right)$ & 37,7 & 30,3 \\
$\mathrm{~K}$ total $\left(\mathrm{g} \mathrm{kg}^{-1}\right)$ & 32,0 & 24,4 \\
Ca total $\left(\mathrm{g} \mathrm{kg}^{-1}\right)$ & 64,2 & 64,0 \\
$\mathrm{Mg}$ total $\left(\mathrm{g} \mathrm{kg}^{-1}\right)$ & 7,8 & 6,9 \\
$\mathrm{~S}$ total $\left(\mathrm{g} \mathrm{kg}^{-1}\right)$ & 3,3 & 2,1 \\
Cu total $\left(\mathrm{mg} \mathrm{kg}^{-1}\right)$ & 233,3 & 106,0 \\
Mn total $\left(\mathrm{mg} \mathrm{kg}^{-1}\right)$ & 194,5 & 122,0 \\
Zn total $\left(\mathrm{mg} \mathrm{kg}^{-1}\right)$ & 308,0 & 289,4 \\
Fe total $\left(\mathrm{mg} \mathrm{kg}^{-1}\right)$ & $2.274,9$ & $1.803,0$ \\
$\mathrm{~B}$ total $\left(\mathrm{mg} \mathrm{kg}^{-1}\right)$ & 137,6 & 131,0 \\
Relação C/ & 6,0 & 14,0 \\
$(\mathrm{C}$ total $/ \mathrm{N} \mathrm{total})$ & & \\
\hline
\end{tabular}


As variáveis analisadas foram: carbono total (CT), nitrogênio total (NT), relação $\mathrm{C} / \mathrm{N}$, densidade do solo (Ds), resistência mecânica do solo à penetração (RSP), conteúdo de água atual (CA), diâmetro médio ponderado de agregados (DMP), diâmetro médio geométrico de agregados (DMG), índice de estabilidade de agregados, porosidade total (PT), macroporosidade (Mac), microporosidade (Mic) e condutividade hidráulica saturada (Ks). Para caracterizar as parcelas e minimizar possíveis erros nos dados amostrais, determinou-se também a textura, pelo método da pipeta, e a densidade de partícula (Dp), pelo método do balão volumétrico.

Na determinação do CT foi utilizado um Analisador de Carbono (Organic Carbon Analyser, TOC-V) - 1500 da SHIMADZU, equipado com módulo de amostrador de sólidos SSM $-1.500{ }^{\circ} \mathrm{C}$, devidamente calibrado (Segnini et al., 2008); o NT foi extraído por digestão sulfúrica, seguido de destilação Kjeldahl. A densidade do solo foi obtida pelo método do anel volumétrico. A porosidade total foi determinada pela soma da macroporosidade (Mac) e microporosidade (Mic) do solo, e estas foram obtidas pelo método da mesa de tensão, na tensão equivalente a seis quilos pascal. A condutividade hidráulica saturada foi determinada pelo método do permeâmetro de carga constante e determinou-se o CA no momento da amostragem pelo método-padrão (gravimétrico). A estabilidade de agregados foi determinada por oscilação via úmida com os agregados retidos entre as peneiras de 4 e $2 \mathrm{~mm}$ de diâmetro. Todas as análises, com exceção do CT, foram determinadas conforme método da Embrapa (1997).

$\mathrm{O}$ efeito dos sistemas em profundidades sobre os atributos do solo foram testados por análise de variância (ANAVA), quando atenderam aos pressupostos de normalidade pelo teste Ryan-Joiner $(p>0,10)$ e variância constante $(p<0,05)$. Em caso de $F$ significativo $(p<0,05)$, foi realizada comparação pareada das médias pelo teste de Tukey $(p<0,05)$, utilizando o software SISVAR 4.6 para Windows (Ferreira, 2000).

\section{RESULTADOS E DISCUSSÃO}

Pelo teste F ( $p>0,05)$ aplicado sobre os dados de textura e densidade de partícula, ficou provado não haver diferença estatística entre as áreas e profundidades, sendo possível então a comparação. As médias e o desvio-padrão de argila, silte e areia total foram de 356,9 $\pm 14,3 \mathrm{~g} \mathrm{~kg}^{-1}, 64,4 \pm 10,3 \mathrm{~g} \mathrm{~kg}^{-1} \mathrm{e} 578,7$ $\pm 13,5 \mathrm{~g} \mathrm{~kg}^{-1}$, respectivamente, e a densidade da partícula, de 2,5 $\pm 0,07 \mathrm{Mg} \mathrm{m}^{-3}$.

$\mathrm{O}$ efeito dos sistemas de manejo em profundidade e sua interferência nos atributos do solo podem ser observados pela significância de F (Quadro 2). Constataram-se, de modo geral, baixos coeficientes de variação, com exceção da condutividade hidráulica saturada (Ks). Esse fato está respaldado por Lima \& Silans (1999), que também evidenciam maior variação do Ks entre amostras de mesmo solo. Isso pode estar relacionado à existência de infiltrações preferenciais em macroporos ou ao longo das raízes (Lima \& Silans, 1999; Silva et al., 2008). Outro fator que pode contribuir para maior variação da Ks é a variabilidade espacial típica das propriedades de movimentação tridimensional da água (Silva et al., 2008).

Quadro 2. Resultado da análise de variância dos atributos de um Latossolo Vermelho-Amarelo, em função do sistema de manejo e da profundidade de amostragem

\begin{tabular}{|c|c|c|c|c|c|}
\hline \multirow{2}{*}{ Atributo } & \multicolumn{3}{|c|}{ Fonte de variação } & \multirow{2}{*}{ CV (MN) } & \multirow{2}{*}{$\mathrm{CV}(\mathrm{P})$} \\
\hline & Manejo (MN) & Profundidade $(\mathrm{P})$ & $\mathbf{M N} \times \mathbf{P}$ & & \\
\hline & & Significância do F & & $\longrightarrow$ & - \\
\hline $\mathrm{CT}\left(\mathrm{g} \mathrm{kg}^{-1}\right)$ & $0,0001^{* *}$ & $0,0000^{* *}$ & $0,0001^{* *}$ & 7,67 & 1,17 \\
\hline $\mathrm{NT}\left(\mathrm{g} \mathrm{kg}^{-1}\right)$ & $0,0044^{* *}$ & $0,0169^{*}$ & $0,0064^{* *}$ & 8,40 & 8,81 \\
\hline Relação C/N & $0,0000^{* *}$ & $0,0000^{* *}$ & $0,0000^{* *}$ & 8,03 & 6,85 \\
\hline $\mathrm{DMP}(\mathrm{mm})$ & $0,0000^{* *}$ & $0,0000^{* *}$ & $0,0057^{* *}$ & 7,55 & 7,70 \\
\hline $\mathrm{DMG}(\mathrm{mm})$ & $0,0000^{* *}$ & $0,0000^{* *}$ & $0,0329^{*}$ & 9,63 & 8,28 \\
\hline IEA $(\%)$ & $0,0000 * *$ & $0,6076 \mathrm{~ns}$ & $0,0312^{*}$ & 2,97 & 3,13 \\
\hline Ds $\left(\mathrm{Mg} \mathrm{kg}^{-1}\right)$ & $0,0083^{* *}$ & $0,0108^{*}$ & $0,0000^{* *}$ & 4,93 & 2,02 \\
\hline $\mathrm{RSP}(\mathrm{MPa})$ & $0,0072^{*}$ & $0,0029^{* *}$ & $0,4809 \mathrm{~ns}$ & 9,95 & 7,39 \\
\hline $\mathrm{CA}\left(\mathrm{cm}^{3} \mathrm{~cm}^{-3}\right)$ & $0,0821 \mathrm{~ns}$ & $0,8922 \mathrm{~ns}$ & $0,7982 \mathrm{~ns}$ & 18,34 & 14,59 \\
\hline $\operatorname{Mac}\left(\mathrm{cm}^{3} \mathrm{~cm}^{-3}\right)$ & $0,0038^{* *}$ & $0,0054^{* *}$ & $0,4139 \mathrm{~ns}$ & 18,65 & 6,22 \\
\hline Mic $\left(\mathrm{cm}^{3} \mathrm{~cm}^{-3}\right)$ & $0,0035^{* *}$ & $0,0106^{*}$ & $0,1111 \mathrm{~ns}$ & 9,16 & 3,14 \\
\hline $\operatorname{Pt}\left(\mathrm{cm}^{3} \mathrm{~cm}^{-3}\right)$ & $0,0057^{* *}$ & $0,0231^{*}$ & $0,0000^{* *}$ & 5,46 & 2,18 \\
\hline $\mathrm{Ks}\left(\mathrm{mm} \mathrm{h}^{-1}\right)$ & $0,0008^{* *}$ & $0,4044 \mathrm{~ns}$ & $0,1589 \mathrm{~ns}$ & 37,45 & 31,02 \\
\hline
\end{tabular}

CT: carbono total; NT: nitrogênio total; DMP: diâmetro médio ponderado de agregados; DMG: diâmetro médio geométrico de agregados; IEA: índice de estabilidade de agregados; DS: densidade do solo; RSP: resistência mecânica do solo à penetração; CA: conteúdo atual de água do solo; Mac: macroporosidade; Mic: microporosidade; Pt: porosidade total; Ks: condutividade hidráulica

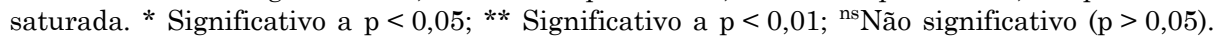


Nota-se que apenas o CA e a Ks não foram influenciados pela profundidade e somente CA não foi influenciado pelo manejo, demonstrando que os demais atributos são sensíveis às alterações do solo tanto devido ao uso quanto em relação à profundidade (Quadro 2). Observa-se que, para CA, os níveis de significância do teste $\mathrm{F}$ foram relativamente altos, mostrando que a umidade no momento da coleta não teve variações significativas - condição essencial para obtenção da resistência do solo à penetração (RSP), uma vez que esta é fortemente influenciada pelo CA no solo (Lima et al., 2007). Entre os atributos que foram modificados pelos sistemas nas profundidades, RSP, Mac e Mic não foram alterados por interação, sistema de manejo e profundidade.

No desdobramento da interação entre sistema e profundidade, verifica-se que os teores de CT decrescem com a profundidade em todos os sistemas, porém isso ocorre em proporções diferentes (Quadro 3). Na camada de $0-10 \mathrm{~cm}$, os maiores teores de CT foram encontrados nos sistemas S1 e S2, seguido por S4 e S3. Contudo, nas demais profundidades, o S4 passa a ter o maior teor de CT. Por outro lado, o teor de NT, que também reduziu em profundidade em todos os sistemas, não diferiu na camada de $0-10 \mathrm{~cm}$, tendo a adubação orgânica proporcionado os mesmos teores de NT do que nos sistemas com somente adubação mineral. Entretanto, na profundidade de $10-30 \mathrm{~cm}$, o teor de NT do S3 foi maior que o dos demais sistemas, mostrando a movimentação de NT no perfil do solo, mesmo que os teores tenham reduzido em profundidade (Quadro 3).

A relação $\mathrm{C} / \mathrm{N}$ do solo foi alterada pelo manejo, com menores valores no $\mathrm{S} 3$ e com tendência de aumento com a profundidade (Quadro 3). Com isso, é possível entender o menor teor de CT no S3, onde o resíduo é fornecido sem passar por compostagem. Isso ocorreu porque durante o processo de compostagem a perda de $\mathrm{N}$ foi intensa, e o $\mathrm{C}$ permaneceu constante, favorecendo o aumento da relação $\mathrm{C} / \mathrm{N}$ na cama compostada (Quadro 1). Os valores de relação $\mathrm{C} / \mathrm{N}$ no solo foram reflexo da relação que havia no material, em que a adição de material orgânico de baixa relação C/N na superfície do solo proporcionou também baixa relação no solo, não contribuindo para aumentar os teores de CT na superfície, e sim podendo promover a redução.

Respostas semelhantes foram encontradas por Costa et al. (2008), trabalhando com cama de peru, e Camilotti et al. (2006), com lodo de esgoto e vinhaça, que não verificaram aumento no CT mesmo com a adição de material orgânico, atribuindo-se isso ao processo de decomposição e mineralização da matéria orgânica do solo. De acordo com Andreola et al. (2000), quando se adiciona material orgânico ao solo, principalmente aqueles de baixa relação $\mathrm{C} / \mathrm{N}$, ocorre inicialmente a ação dos microrganismos decompositores, que passam a decompor, além do material adicionado, o $\mathrm{C}$ de baixa qualidade preexistente. Por outro lado, o C contido no composto orgânico é mais estável e de difícil degradação, uma vez que parte encontrase humificada. Por essa razão, a aplicação sucessiva de composto orgânico ao solo contribui para elevação paulatina dos teores de $\mathrm{CT}$.

Nota-se que em plantio direto há naturalmente maior teor de CT em superfície, pelo acúmulo de resíduo orgânico, e menor decomposição, por não haver revolvimento do solo (Tormena et al., 2004), o que explica o teor médio de CT no S2 igual ao S1 na camada mais superficial do solo, mostrando que é possível com plantio direto manter altos os níveis de CT no solo. Outro fato relevante é que em S2 e S4 houve rotação de cultura com o milheto - gramínea com sistema

Quadro 3. Carbono total (CT), nitrogênio total (NT) e relação C/N de um Latossolo Vermelho-Amarelo, em função do sistema de manejo e profundidade de amostragem

\begin{tabular}{|c|c|c|c|c|c|c|}
\hline \multirow{2}{*}{ Atributo } & \multirow{2}{*}{ Profundidade } & \multicolumn{4}{|c|}{ Sistema de Manejo ${ }^{(1)}$} & \multirow{2}{*}{ Média } \\
\hline & & S1 & S2 & S3 & $\mathbf{S} 4$ & \\
\hline \multirow{5}{*}{$\mathrm{CT}\left(\mathrm{g} \mathrm{kg}^{-1}\right)$} & $\mathrm{cm}$ & & & & & \\
\hline & $0-10$ & $37,02 \mathrm{Aa}$ & $38,18 \mathrm{Aa}$ & $25,37 \mathrm{Ca}$ & $30,12 \mathrm{Ba}$ & 32,67 \\
\hline & $10-20$ & $25,28 \mathrm{AB} \mathrm{b}$ & $22,30 \mathrm{Bb}$ & $18,68 \mathrm{Cb}$ & $27,47 \mathrm{Aab}$ & 23,43 \\
\hline & $20-30$ & $21,92 \mathrm{ABb}$ & $17,23 \mathrm{Cc}$ & $15,73 \mathrm{Cb}$ & $24,03 \mathrm{Ab}$ & 19,73 \\
\hline & Média & 28,07 & 25,90 & 19,93 & 27,21 & 25,28 \\
\hline \multirow[t]{4}{*}{$\mathrm{NT}\left(\mathrm{g} \mathrm{kg}^{-1}\right)$} & $0-10$ & 8,39 Aa & $7,45 \mathrm{Aa}$ & 8,39 Aa & 7,57 Aa & 7,95 \\
\hline & $10-20$ & $5,00 \mathrm{Bab}$ & $4,68 \mathrm{Bb}$ & 6,92 Aab & $4,21 \mathrm{Bb}$ & 5,20 \\
\hline & $20-30$ & $3,99 \mathrm{Bb}$ & $2,25 \mathrm{Cc}$ & $6,06 \mathrm{Ab}$ & $3,81 \mathrm{BCb}$ & 4,03 \\
\hline & Média & 5,79 & 4,79 & 7,12 & 5,20 & 5,72 \\
\hline \multirow[t]{4}{*}{ Relação C/N } & $0-10$ & $4,41 \mathrm{ABb}$ & $5,12 \mathrm{Ab}$ & $3,02 \mathrm{Ca}$ & $3,98 \mathrm{Bb}$ & 4,13 \\
\hline & $10-20$ & $5,05 \mathrm{Bab}$ & $4,76 \mathrm{Bb}$ & $2,70 \mathrm{Ca}$ & $6,52 \mathrm{Aa}$ & 4,76 \\
\hline & $20-30$ & $5,49 \mathrm{Ca}$ & $7,66 \mathrm{Aa}$ & $2,59 \mathrm{Da}$ & $6,30 \mathrm{Ba}$ & 5,51 \\
\hline & Média & 4,99 & 5,85 & 2,77 & 5,60 & 4,80 \\
\hline
\end{tabular}

\footnotetext{
(1) S1: Cerrado nativo sem alteração antrópica; S2: plantio direto com adubação mineral; S3: plantio direto com adição de cama de frango crua; S4: plantio direto com adição de cama de frango compostada. Médias seguidas de mesma letra, maiúscula na linha e minúscula na coluna, não diferem entre si pelo teste de Tukey $(p<0,05)$.
} 
radicular agressivo e que agrega ao solo $\mathrm{C}$ estável e de alta relação C/N (Foloni et al., 2008). Já no sistema S3 houve basicamente sucessão de soja e milho, com a soja implantada anualmente favorecendo a decomposição dos resíduos e, por consequência, a redução dos teores de CT. O maior teor de CT no $\mathrm{S} 4$ em profundidade deixa clara a importância da adição de resíduo orgânico compostado quando se visa aumentar os níveis de $\mathrm{C}$ em profundidade.
No caso da Ds, o desdobramento da interação entre sistemas de manejo e profundidades (Quadro 4) evidenciou que na camada de $0-10 \mathrm{~cm}$ estavam os solos mais adensados, obedecendo à seguinte ordem: S3, seguido de S4 e S2, tendo o Cerrado nativo a menor Ds. Esse resultado indica que mesmo com o CT no S2 e S4 semelhante ao da área não perturbada, isso não foi suficiente para impedir o adensamento do solo, o que pode estar relacionado ao tráfego de máquinas

Quadro 4. Densidade do solo (Ds), resistência do solo à penetração (RSP), conteúdo de água do solo (CA), diâmetro médio ponderado (DMP), diâmetro médio geométrico (DMG), índice de estabilidade de agregados (IEA), macroporosidade (Mac), microporosidade (Mic), porosidade total (PT) e condutividade hidráulica saturada (Ks) de um Latossolo Vermelho-Amarelo, em função do sistema de manejo e da profundidade de amostragem

\begin{tabular}{|c|c|c|c|c|c|c|}
\hline \multirow{2}{*}{ Atributo } & \multirow{2}{*}{ Profundidade } & \multicolumn{5}{|c|}{ Sistema de Manejo ${ }^{(1)}$} \\
\hline & & S1 & S2 & S3 & S4 & Média \\
\hline $\mathrm{Ds}\left(\mathrm{Mg} \mathrm{m}^{-3}\right)$ & $\begin{array}{c}\mathrm{cm} \\
0-10 \\
10-20 \\
20-30 \\
\text { Média }\end{array}$ & $\begin{array}{l}1,14 \mathrm{Cb} \\
1,23 \mathrm{BCa} \\
1,25 \mathrm{Aa} \\
1,21\end{array}$ & $\begin{array}{l}1,22 \mathrm{Ba} \\
1,29 \mathrm{ABa} \\
1,24 \mathrm{Aa} \\
1,25\end{array}$ & $\begin{array}{l}1,39 \mathrm{Aa} \\
1,31 \mathrm{Aab} \\
1,28 \mathrm{Ab} \\
1,33\end{array}$ & $\begin{array}{l}1,29 \mathrm{Ba} \\
1,21 \mathrm{Cab} \\
1,24 \mathrm{Aa} \\
1,25\end{array}$ & $\begin{array}{l}1,26 \\
1,26 \\
1,25 \\
1,26\end{array}$ \\
\hline $\mathrm{RSP}(\mathrm{MPa})$ & $\begin{array}{r}0-10 \\
10-20 \\
20-30 \\
\text { Média }\end{array}$ & $\begin{array}{l}2,46 \\
2,79 \\
2,46 \\
2,57 \mathrm{~B}\end{array}$ & $\begin{array}{l}4,04 \\
4,08 \\
3,41 \\
3,84 \mathrm{~A}\end{array}$ & $\begin{array}{l}4,17 \\
4,57 \\
3,28 \\
4,01 \mathrm{~A}\end{array}$ & $\begin{array}{l}3,19 \\
4,20 \\
2,96 \\
3,45 \mathrm{AB}\end{array}$ & $\begin{array}{l}3,47 \mathrm{ab} \\
3,91 \mathrm{a} \\
3,03 \mathrm{~b} \\
3,47\end{array}$ \\
\hline $\mathrm{CA}\left(\mathrm{cm}^{3} \mathrm{~cm}^{-3}\right)$ & $\begin{array}{r}0-10 \\
10-20 \\
20-30 \\
\text { Média }\end{array}$ & $\begin{array}{l}0,139 \\
0,144 \\
0,148 \\
0,143\end{array}$ & $\begin{array}{l}0,110 \\
0,111 \\
0,124 \\
0,115\end{array}$ & $\begin{array}{l}0,998 \\
0,105 \\
0,111 \\
0,105\end{array}$ & $\begin{array}{l}0,115 \\
0,117 \\
0,130 \\
0,121\end{array}$ & $\begin{array}{l}0,116 \\
0,119 \\
0,128 \\
0,121\end{array}$ \\
\hline $\mathrm{DMP}(\mathrm{mm})$ & $\begin{array}{r}0-10 \\
10-20 \\
20-30 \\
\text { Média }\end{array}$ & $\begin{array}{l}2,68 \mathrm{Aa} \\
2,57 \mathrm{Aa} \\
2,66 \mathrm{Aa} \\
2,64\end{array}$ & $\begin{array}{l}2,34 \mathrm{Ba} \\
1,96 \mathrm{Cb} \\
1,75 \mathrm{Cb} \\
2,02\end{array}$ & $\begin{array}{l}1,73 \mathrm{Ca} \\
1,48 \mathrm{Db} \\
1,62 \mathrm{Cab} \\
1,61\end{array}$ & $\begin{array}{l}2,58 \mathrm{ABa} \\
2,26 \mathrm{Bb} \\
2,33 \mathrm{Bb} \\
2,39\end{array}$ & $\begin{array}{l}2,33 \\
2,07 \\
2,09 \\
6,49\end{array}$ \\
\hline $\mathrm{DMG}(\mathrm{mm})$ & $\begin{array}{r}0-10 \\
10-20 \\
20-30 \\
\text { Média }\end{array}$ & $\begin{array}{l}2,33 \mathrm{Aa} \\
2,24 \mathrm{Aa} \\
2,40 \mathrm{Aa} \\
2,32\end{array}$ & $\begin{array}{l}1,75 \mathrm{Ba} \\
1,31 \mathrm{Cb} \\
1,27 \mathrm{Cb} \\
1,45\end{array}$ & $\begin{array}{l}1,09 \mathrm{Ca} \\
0,95 \mathrm{Da} \\
0,98 \mathrm{Ca} \\
1,01\end{array}$ & $\begin{array}{l}2,21 \mathrm{Aa} \\
1,73 \mathrm{Bb} \\
1,73 \mathrm{Bb} \\
1,89\end{array}$ & $\begin{array}{l}1,84 \\
1,56 \\
1,60 \\
1,67\end{array}$ \\
\hline IEA (\%) & $\begin{array}{r}0-10 \\
10-20 \\
20-30 \\
\text { Média }\end{array}$ & $\begin{array}{l}95,75 \mathrm{Aa} \\
97,68 \mathrm{Aa} \\
98,16 \mathrm{Aa} \\
97,20\end{array}$ & $\begin{array}{l}92,38 \mathrm{Aab} \\
88,68 \mathrm{Bb} \\
93,09 \mathrm{Ba} \\
91,38\end{array}$ & $\begin{array}{l}85,95 \mathrm{Ba} \\
88,54 \mathrm{Ba} \\
86,41 \mathrm{Ca} \\
86,97\end{array}$ & $\begin{array}{l}96,50 \mathrm{Aa} \\
93,51 \mathrm{Aa} \\
94,06 \mathrm{ABa} \\
94,69\end{array}$ & $\begin{array}{l}92,64 \\
92,10 \\
92,93 \\
92,56\end{array}$ \\
\hline $\operatorname{Mac}\left(\mathrm{cm}^{3} \mathrm{~cm}^{-3}\right)$ & $\begin{array}{r}0-10 \\
10-20 \\
20-30 \\
\text { Média }\end{array}$ & $\begin{array}{l}0,201 \\
0,186 \\
0,183 \\
0,190 \mathrm{~A}\end{array}$ & $\begin{array}{l}0,105 \\
0,085 \\
0,090 \\
0,093 \mathrm{C}\end{array}$ & $\begin{array}{l}0,087 \\
0,078 \\
0,083 \\
0,083 \mathrm{C}\end{array}$ & $\begin{array}{l}0,152 \\
0,140 \\
0,144 \\
0,145 \mathrm{~B}\end{array}$ & $\begin{array}{l}0,136 \mathrm{a} \\
0,123 \mathrm{~b} \\
0,125 \mathrm{~b} \\
0,128\end{array}$ \\
\hline $\operatorname{Mic}\left(\mathrm{cm}^{3} \mathrm{~cm}^{-3}\right)$ & $\begin{array}{r}0-10 \\
10-20 \\
20-30 \\
\text { Média }\end{array}$ & $\begin{array}{l}0,354 \\
0,329 \\
0,332 \\
0,338 \mathrm{D}\end{array}$ & $\begin{array}{l}0,417 \\
0,423 \\
0,421 \\
0,420 \mathrm{~A}\end{array}$ & $\begin{array}{l}0,354 \\
0,400 \\
0,411 \\
0,388 \mathrm{~B}\end{array}$ & $\begin{array}{l}0,336 \\
0,350 \\
0,363 \\
0,350 \mathrm{C}\end{array}$ & $\begin{array}{l}0,365 \mathrm{~b} \\
0,375 \mathrm{ab} \\
0,382 \mathrm{a} \\
0,374\end{array}$ \\
\hline $\operatorname{Pt}\left(\mathrm{cm}^{3} \mathrm{~cm}^{-3}\right)$ & $\begin{array}{r}0-10 \\
10-20 \\
20-30 \\
\text { Média }\end{array}$ & $\begin{array}{l}0,555 \mathrm{Aa} \\
0,515 \mathrm{Ab} \\
0,516 \mathrm{Ab} \\
0,529\end{array}$ & $\begin{array}{l}0,522 \mathrm{Ba} \\
0,508 \mathrm{ABa} \\
0,511 \mathrm{Aa} \\
0,514\end{array}$ & $\begin{array}{l}0,441 \mathrm{Db} \\
0,478 \mathrm{Ca} \\
0,494 \mathrm{Aa} \\
0,471\end{array}$ & $\begin{array}{l}0,488 \mathrm{Ca} \\
0,490 \mathrm{BCa} \\
0,506 \mathrm{Aa} \\
0,495\end{array}$ & $\begin{array}{l}0,501 \\
0,498 \\
0,498 \\
0,499\end{array}$ \\
\hline $\mathrm{Ks}\left(\mathrm{mm} \mathrm{h}^{-1}\right)$ & $\begin{array}{r}0-10 \\
10-20 \\
20-30 \\
\text { Média }\end{array}$ & $\begin{array}{c}106,98 \\
90,3 \\
94,66 \\
97,31 \mathrm{~A}\end{array}$ & $\begin{array}{l}\quad 8,2 \\
10,48 \\
14,3 \\
10,99 \mathrm{C}\end{array}$ & $\begin{array}{l}\quad 7,94 \\
13,1 \\
16,46 \\
12,5 \mathrm{C}\end{array}$ & $\begin{array}{l}31,22 \\
35,2 \\
33,64 \\
33,35 \mathrm{~B}\end{array}$ & $\begin{array}{l}38,59 \\
37,27 \\
39,76 \\
38,54\end{array}$ \\
\hline
\end{tabular}

(1) S1: Cerrado nativo sem alteração antrópica; S2: plantio direto com adubação mineral; S3: plantio direto com adição de cama de frango crua; S4: plantio direto com adição de cama de frango compostada. Médias seguidas de mesma letra, maiúscula na linha e minúscula na coluna, não diferem entre si pelo teste de Tukey $(p<0,05)$. 
observado em sistemas de plantio direto. $\mathrm{O}$ fato não se repete em profundidade: na camada de $10-20 \mathrm{~cm}$ a menor Ds ocorre no $\mathrm{S} 4$ e não há diferença entre os sistemas na camada de $20-30 \mathrm{~cm}$, com menor alteração em subsuperfície.

Dessa forma, não foi possível encontrar efeito da cama de frango na redução da Ds, o que corrobora os resultados de Adeli et al. (2007) e Benjamin et al. (2008). Os resultados encontrados neste estudo provavelmente se devem à baixa dose de material orgânico utilizada, que não foi suficiente para promover redução na Ds superficial. Contudo, para solos de textura franco-argilosa, classe textural deste estudo, a densidade crítica situa-se entre 1,4 e $1,5 \mathrm{Mg} \mathrm{m}^{-3}$ (Reichert et al., 2003), e a densidade do solo avaliada nas áreas cultivadas esteve entre $1,21 \mathrm{e}$ $1,39 \mathrm{Mg} \mathrm{m}^{-3}$, portanto, ligeiramente inferior ao limite crítico proposto.

No estudo da Ds em profundidade, observa-se que no Cerrado nativo essa propriedade tende a ser maior na camada de 10 a $30 \mathrm{~cm}$, enquanto nas áreas cultivadas, S2 e S4, ocorre o inverso, ou seja, a Ds tende a ser menor em subsuperfície. Isso ocorre devido ao adensamento natural dos solos do Cerrado, que apresenta diminuição da matéria orgânica em profundidade e está submetida ao peso das camadas subjacentes (Souza \& Alves, 2003), ao passo que nas áreas submetidas ao plantio direto as camadas superficiais são compactadas, devido ao arranjamento das partículas do solo atribuído ao tráfego de máquinas agrícolas, mesmo sem o revolvimento do solo (Tormena et al., 2004).

A RSP foi menor no $\mathrm{S} 1 \mathrm{em}$ todas as profundidades estudadas, independentemente do sistema de manejo adotado (Quadro 4). Houve aumento de RSP da camada de $0-10 \mathrm{~cm}$ para a de $10-20 \mathrm{~cm}$, seguido de redução na camada de $20-30 \mathrm{~cm}$, evidenciando compactação da camada intermediária. Nota-se que, de modo geral, entre os sistemas cultivados não há diferença, evidenciando novamente alterações antrópicas e que a dose utilizada do resíduo, independentemente da forma de aplicação, crua ou compostada, não foi suficiente para reduzir a RSP, quando comparado com a área sem aplicação. Os resultados encontrados para essa variável foram semelhantes aos da Ds, não se verificando influência da cama de frango em ambas as propriedades e menores valores na área não perturbada, corroborando assim os resultados de Araújo et al. (2004).

Verificam-se valores relativamente altos de RSP, entre 2,46 e $4,57 \mathrm{MPa}$, quando comparados ao valor de 2,0 $\mathrm{MPa}$ - considerado crítico para crescimento e desenvolvimento ótimo da maioria das culturas (Taylor et al., 1966); entretanto, esse limite é motivo de discussão entre pesquisadores. Richart et al. (2005) sugerem, em sua revisão, valores variando de 1,0 a 5,0 MPa como limites críticos para RSP em diferentes tipos de solo. O baixo CA no momento da amostragem também justifica os altos valores de RSP. Segundo
Lima et al. (2007), existe alta dependência dos valores de RSP em relação ao CA, e essa relação ocorre de maneira inversa, ou seja, quando se aumenta o CA no solo, há redução dos valores de RSP. Todavia, considerando que a diferença no CA entre os sistemas e a profundidade não foi significativa neste estudo, as condições de umidade podem ser consideradas homogêneas, e os valores de resistência são aceitáveis e podem ser comparados.

Quanto à avaliação dos agregados do solo mediante o diâmetro médio ponderado (DMP), diâmetro médio geométrico (DMG) e índice de estabilidade de agregados (IEA), nota-se que, de modo geral, no $\mathrm{S} 1$ e S4 a estrutura do solo encontra-se mais estável e há maior formação de macroagregados em comparação com S2 e S3 (Quadro 4). Assim, apesar de a cama de frango crua não influenciar a Ds e RSP, quando esta é fornecida de forma compostada, é possível melhor estruturação do solo, tal como observada na área não manejada. Esse fato pode estar relacionado ao CT mais estável do material compostado em relação à cama de frango crua e à adubação mineral, o que favorece a atividade biológica e possibilita aumento de ligações orgânicas ou agentes estabilizantes para macroagregação do solo (Angers et al.,1992).

A ação do $\mathrm{C}$ reduz a molhabilidade dos agregados, reduzindo as taxas de umedecimento e desestruturação, pela rápida expulsão do ar, e aumenta a coesão interna deles, tornando-os mais estáveis (Chenu et al., 2000). Agregados mais estáveis proporcionados pelo CT foram verificados por Barzegar et al. (2002) e Adeli et al. (2007). Estes últimos autores constataram contribuição da cama de frango na agregação do solo na ordem de $34 \%$ após três anos de aplicação no algodoeiro. A maior estabilidade de agregados em água e agregados de maior tamanho são propriedades desejáveis nos solos cultivados, uma vez que estão diretamente ligadas ao processo erosivo, podendo refletir em maior resistência do solo à erosão (Castro Filho \& Logan, 1991; Castro Filho et al., 1998) em decorrência da maior resistência à desagregação e dispersão.

Quando se comparam as profundidades, verificase redução no diâmetro dos agregados nos sistemas cultivados, em relação ao sistema não manejado (Quadro 4), ratificando alteração na estrutura do solo com as práticas de manejo. Sugere-se também que o $\mathrm{CT}$ presente em solo sob mata nativa (S1) seja mais estável que o CT observado em sistemas antropizados, conforme relatado na literatura (Andreola et al., 2000; Benjamin et al., 2008).

Em relação à distribuição dos tamanhos dos poros do solo, observa-se que os valores de macroporosidade (Mac) situaram-se entre 0,085 e 0,201 $\mathrm{cm}^{3} \mathrm{~cm}^{3}$, sendo sempre maior no $\mathrm{S} 1$ seguido do $\mathrm{S} 4$; independentemente do sistema, houve tendência de redução da Mac em profundidade (Quadro 5). Para microporosidade (Mic), os valores variaram de 0,329 a $0,423 \mathrm{~cm}^{3} \mathrm{~cm}^{3}$ e foi observada resposta diferente em relação à Mac, sendo sempre maior no $\mathrm{S} 2$ seguido do $\mathrm{S} 3$; independentemente 
do sistema, houve tendência de aumento da Mic em profundidade (Quadro 4).

Os valores de Mac e Mic refletiram diretamente na porosidade total (Pt) (Quadro 4), que variou de 0,441 a $0,555 \mathrm{~cm}^{3} \mathrm{~cm}^{3}$. Na camada de $0-10 \mathrm{~cm}$ o maior valor foi encontrado no S1 e S2; na camada de 10 $20 \mathrm{~cm}$ a maior Pt foi encontrada no S1; e na camada de 20-30 cm não houve diferença entre os sistemas, validando a menor alteração física em subsuperfície. Houve tendência de a Pt diminuir no S1 e aumentar no S3 em profundidade, não sendo significativo nos demais sistemas estudados. Isso provavelmente ocorreu devido à resposta da Ds, que tendeu a aumentar no S1 e diminuir nos demais sistemas quando houve estudo em profundidade, corroborando os resultados de Souza \& Alves (2003), que mostram relação inversa entre $\mathrm{Ds}$ e $\mathrm{Pt}$.

De maneira simplificada, o $\mathrm{S} 4$ foi o que mais se aproximou do Cerrado nativo quanto à Mac e Mic; entretanto, o $\mathrm{S} 2$ foi mais semelhante em relação à $\mathrm{Pt}$, sobretudo devido ao aumento da Mic. Por outro lado, independentemente das considerações estatísticas, pode-se verificar que a prática de cultivo promoveu modificações nas propriedades físicas do solo, com o aumento da Ds e da Mic e redução da Mac, e consequente redução da $\mathrm{Pt}$ do solo em relação à área de Cerrado, o que também foi observado por Souza \& Alves (2003) e Silva et al. (2008). Solos com vegetação nativa favorecem a formação de uma rede de poros mais contínua, devido à maior estabilidade do CT $\mathrm{e}$ atividade da raiz, quando comparado a sistemas cultivados (Benjamim et al., 2008).

$\mathrm{Na}$ análise dos valores médios de condutividade hidráulica do solo saturado (Ks), expostos no quadro 4, observa-se que não houve diferença na camada de 0 $30 \mathrm{~cm}$, independentemente do sistema estudado. Por outro lado, essa propriedade foi significativamente alterada pelo sistema de manejo, reforçando a ideia de alteração estrutural dos solos pelo uso, principalmente em relação a forma, tamanho e continuidade dos poros, que alteram a dinâmica da água no solo (Silva et al., 2008) mesmo com altos teores de CT fornecidos pela adubação orgânica.

A condutividade hidráulica do solo saturado (Ks) foi drasticamente alterada pelo manejo, tendo havido reduções de 57 a $84 \%$ nos seus valores no S4 e S2, respectivamente, comparativamente à Ks do S1. Isso se deve à redução da Mac, em razão do aumento da compactação do solo. Essa redução na Ks, sob efeito da compactação, é relatada por Silva et al. (2008). A Ks teve comportamento inverso ao da RSP, como esperado, pois, enquanto a primeira diminui, em razão da menor quantidade de poros para infiltração de água, a segunda tende a aumentar. Contudo, apesar de a ação antrópica ter prejudicado a movimentação de água no solo, possivelmente por alterar a continuidade natural dos poros, pode-se inferir que a adubação orgânica - no caso em particular, a cama de frango compostada - minimizou os efeitos dessa antropização, uma vez que foi o sistema que mais se aproximou das condições naturais. Barzegar et al. (2002), ao estudarem a influência de tipos de materiais orgânicos nas propriedades físicas do solo, encontraram diferenças na contribuição da Ks entre os materiais, confirmando as respostas encontradas neste estudo, uma vez que a cama de frango crua não teve efeito sobre as propriedades estudadas, ao passo que a cama de frango compostada, de maneira geral, foi a que mais influenciou as características do solo, equivalendo-se, em muitos parâmetros analisados, ao Cerrado nativo.

As respostas encontradas neste estudo evidenciaram a importância da compostagem do resíduo para posterior aplicação nas lavouras, fato raro atualmente, justificando as baixas respostas encontradas na literatura para a cama de frango como condicionador dos atributos físicos do solo. Deve-se ressaltar que em solos mais degradados há possibilidade de maior resposta à adição de adubo orgânico (Costa et al., 2009). Considera-se também que a aplicação sucessiva de resíduos orgânicos na substituição de adubos minerais vai, ao longo do tempo, contribuir para amenizar os efeitos do cultivo intensivo do solo. Além das aplicações de resíduos orgânicos, convém ressaltar que as respostas encontradas podem estar relacionadas às diferenças de rotação de culturas entre os sistemas de manejo S2, S3 e S4, os quais mostraram diferenças consideráveis nos anos que antecederam ao estudo.

\section{CONCLUSÕES}

1. Os sistemas de cultivo proporcionaram degradação dos atributos do solo, a qual foi inferida pelos menores valores de carbono total, diâmetro e estabilidade de agregados, macroporosidade e condutividade hidráulica saturada e pelos maiores valores de densidade do solo, resistência do solo à penetração e microporosidade, comparativamente à área com vegetação nativa.

2. Os sistemas que possibilitaram maiores alterações dos atributos físicos do solo foram, em ordem crescente: adubação com cama de frango crua, adubação convencional e adubação com cama de frango compostada.

3. A cama de frango crua proporcionou maior teor de nitrogênio total no solo, enquanto a cama de frango compostada proporcionou ao solo teor de carbono total e atributos físicos mais semelhantes às condições naturais.

\section{LITERATURA CITADA}

ADELI, A.; SISTANI, K.R.; ROWE, D.E. \& TEWOLDE, H. Effects of broiler litter on soybean production and soil nitrogen and phosphorus concentrations. Agron. J. 97:314-321, 2005. 
ADELI, A.; SISTANI, K.R. \& ROWE, D.E. \& TEWOLDE, H. Effects of broiler litter applied to no-till and tillage cotton on selected soil properties. Soil Sci. Soc. Am. J., 71:974 983, 2007.

ANDREOLA, F.; COSTA, L.M. \& OLSZEVSKI, N. Influência da cobertura vegetal de inverno e da adubação orgânica $\mathrm{e}$, ou, mineral sobre as propriedades físicas de uma terra roxa estruturada. R. Bras. Ci. Solo, 24:857-865, 2000.

ANGERS, D.A.; PESANT, A. \& VIGNEUX, J. Early cropping - induced changes in soil aggregation, organic matter and microbial biomass. Soil Sci. Soc. Am. J., 56:115-119, 1992.

ARAÚJO, M.A.; TORMENA, C.A. \& SILVA, A.P. Propriedades físicas de um Latossolo Vermelho distrófico cultivado e sob mata nativa. R. Bras. Ci. Solo, 28:337-345, 2004.

BARZEGAR, A.R.; YOUSEFI, A. \& DARYASHENAS, A. The effect of addition of different amounts and types of organic materials on soil physical properties and yield of wheat. Plant Soil, 247:295-301, 2002.

BENJAMIN, J.G.; MIKHA, M.M. \& VIGIL, M.F. Organic carbon effects on soil physical and hydraulic properties in a semiarid climate. Soil Sci. Soc. Am. J., 72:1357-1362, 2008.

BIANCHINI, A.; MAIA, J.C.M.; MAGALHAES, P.S.G.; CAPELLI, N. \& UMEZU, C.K. Penetrógrafo eletrônico automático. R. Bras. Eng. Agric. Amb., 6:332-336, 2002.

BOATENG, S.A.; ZICKERMANN, J. \& KORNAHRENS, M. Poultry manure effect on growth and yield of maize. West Africa J. Appl. Ecol., 9:1-11, 2006.

CAMILOTTI, F.; ANDRIOLI, I.; MARQUES, M.O.; SILVA, A.R.; TASSO JUNIOR, L.C. \& NOBILES, F.O. Atributos físicos de um Latossolo cultivado com cana-de-açúcar após aplicações de lodo de esgoto e vinhaça. R. Eng. Agríc., 26:738-747, 2006.

CASTRO FILHO, C. \& LOGAN, T.J. Liming effects on the stability and erodibility of some Brazilian Oxisols. Soil Sci. Soc. Am. J., 55:1407-1413, 1991.

CASTRO FILHO, C.; MUZILLI, O. \& PODANOSCHI, A.L Estabilidade dos agregados e sua relação com o teor de carbono orgânico num Latossolo Roxo distrófico, em função de sistemas de plantio, rotações de culturas e métodos de preparo das amostras. R. Bras. Ci. Solo, 22:527538, 1998

CELIK, I.; ORTAS, I. \& KILIC, S. Effects of compost, mycorrhiza, manure and fertilize on some physical properties of a Chromoxerert soil. Soil Tillage Res., 78:5967, 2004.

CHENU, C.; Le BISSONNAIS, Y. \& ARROUAYS, D. Organic matter influence on clay wettability and soil aggregate stability. Soil Sci. Soc. Am. J., 64:1479-1486, 2000.

COSTA, A.M.; RIBEIRO, B.T.; SILVA, A.A. \& BORGES E.N Estabilidade de agregados de um latossolo vermelho tratado com cama de peru. R. Ci. Agrotec., 32:73-79, 2008.
COSTA, A.M.; BORGES, E.N.; SILVA, A.A.; NOLLA, A. \& GUIMARÃES, E.C. Potencial de recuperação física de um Latossolo Vermelho, sob pastagem degradada, influenciado pela aplicação de cama de frango. R. Ci. Agrotec., 33:1991-1998, 2009.

EMPRESA BRASILEIRA DE PESQUISA AGROPECUÁRIA EMBRAPA. Centro Nacional de Pesquisa de Solos. Manual de métodos de análise de solo. 2.ed. Rio de Janeiro, 1997. $212 \mathrm{p}$.

EMPRESA BRASILEIRA DE PESQUISA AGROPECUÁRIA EMBRAPA. Centro Nacional de Pesquisa de Solos. Sistema brasileiro de classificação de solos. 2.ed. Rio de Janeiro, 2006. 306p.

FERREIRA, D.F. Análise estatística por meio do SISVAR (Sistema para Análise de Variância) para Windows versão 4.0. In: REUNIÃO ANUAL DA REGIÃO BRASILEIRA DA SOCIEDADE INTERNACIONAL DE BIOMETRIA, 45., São Carlos, 2000. Anais... São Carlos, Universidade Federal de São Carlos, 2000. p.255-258.

FOLONI, J.S.S.; GARCIA, R.A.; TIRITAN, C.S. \& SILVA, A.S.J. Adubação nitrogenada e qualidade dos restos vegetais de milheto e aveia preta. Agrarian, 1:45-57, 2008.

FRANZLUEBBERS, A.J.; STUEDEMANN， J.A. \& WILKINSON. S.R. Bermudagrass management in the Southern Piedmont USA. I. Soil and surface residue carbon and sulfur. Soil Sci. Soc. Am. J., 65:834-841, 2001.

GIROTTO, A.F. \& MIELI, M. Situação atual e tendências para a avicultura de corte nos próximos anos. Brasília, Embrapa, 2004

LIMA, C.A.G. \& SILANS, A.P. Variabilidade espacial da infiltração de água no solo. Pesq. Agropec. Bras., 34:23112320, 1999.

LIMA, C.L.R.; REICHERTI, J.M.; REINERTI, D.J.; SUZUK, L.E.A.S. \& DALBIANCO, L. Densidade crítica ao crescimento de plantas considerando água disponível e resistência à penetração de um Argissolo Vermelho distrófico arênico. R. Ci. Rural, 37:1166-1169, 2007.

LUNARDI NETO, A.; ALBUQUERQUE, J.A.; ALMEIDA, J.A.; MAFRA, A.L.; MEDEIROS, J.C. \& ALBERTON, A. Atributos físicos do solo em área de mineração de carvão influenciados pela correção da acidez, adubação orgânica e revegetação. R. Bras. Ci. Solo, 1379-1388, 2008.

MOSADDEGHI, M.R.; MAHBOUBI, A.A. \& SAFADOUST, A. Short-term effects of tillage and manure on some soil physical properties and maize root growth in a sandy loam soil in western Iran. Soil Tillage Res., 104:173-179, 2009

REICHERT, J.M.; REINERT, D.J. \& BRAIDA, J.A. Qualidade dos solos e sustentabilidade de sistemas agrícolas. R. Ci. Amb., 27:29-48, 2003.

RICHART, A.; TAVARES FILHO, J.; BRITO, O.R.; LLANILLO, R.F. \& FERREIRA, R. Compactação do solo: Causas e efeitos. Semina: Ci. Agric., 26:321-344, 2005.

SEGNINI, A.; SANTOS, L.M.; SILVA, W.T.L.; MARTIN-NETO, L.; BORATO, C.E.; MELO, W.J. \& BOLONHEZI, D. Estudo comparativo de métodos para a determinação da concentração de carbono em solos com altos teores de $\mathrm{Fe}$ (Latossolos). Química Nova, 31:94-97, 2008. 
SILVA, G.J.; VALADÃO JUNIOR, D.D.; BIANCHINI, A.; AZEVEDO, E.C. \& MAIA, J.C.S. Variação de atributos físico-hídricos em Latossolo Vermelho-Amarelo do Cerrado mato-grossense sob diferentes formas de uso. R. Bras. Ci. Solo, 32:2135-2143, 2008.

SANTOS, C.C.; BELLINGIERI, P.A. \& FREITAS, J.C. Efeito da aplicação de compostos orgânicos de cama de frango nas propriedades químicas de um Latossolo Vermelho Escuro cultivado com sogro granífero [Sorghum bicolor (L.) Moench]. R. Cient., 32:134-140, 2004.

SOUZA, Z.M. \& ALVES, M.C. Propriedades físicas e teor de matéria orgânica em um Latossolo Vermelho de Cerrado sob diferentes usos e manejos. R. Acta Sci., 25:27-34, 2003.
TAYLOR, H.M.; ROBERTSON, G.M. \& PARKER, J.J. Soil strength root penetration relations for medium to coarse textured soil materials. Soil Sci., 102:18-22, 1966.

TORMENA, C.A.; FRIEDRICH, R.; PINTRO, J.C.; COSTA, A.C.S. \& FIDALSKI, J. Propriedades físicas e taxa de estratificação de carbono orgânico num Latossolo Vermelho após dez anos sob dois sistemas de manejo. R. Bras. Ci. Solo, 28:1023-1031, 2004. 